\title{
Adultrap: Descrição de armadilha para adulto de Aedes aegypti (Diptera, Culicidae)
}

\author{
João Edson Donatti ${ }^{1} \&$ Almério de Castro Gomes ${ }^{2}$
}

\begin{abstract}
${ }^{1}$ Rua Curitiba 1924, Bairro Zona 2, 87200-000 Cianorte-PR, Brasil.
${ }^{2}$ Departamento de Epidemiologia, Faculdade de Saúde Pública da Universidade de São Paulo. Av. Dr. Arnaldo 715, 01246-904, São Paulo-SP, Brasil. agcastro@usp.br
\end{abstract}

\begin{abstract}
Adultrap: Description of adult trap of Aedes aegypti (Diptera, Culicidae). The Adultrap is a new kind of trap for capturing Aedes aegypti. It has a spherical shape and dark color. It consists of three chambers: one for the bait, one for entrance of the adult mosquito, and another one to keep the mosquitoes inside the trap. Either laboratory and field works showed that the trap presented positivity for Ae. aegypti adult. The test suggested more studies to evaluate the especificity of the trap to catch this species.
\end{abstract}

KEYWORDS. Adult; mosquitoes; trap.

RESUMO. Adultrap: Descrição de armadilha para adulto de Aedes aegypti (Diptera, Culicidae). A Adultrap é uma nova armadilha para capturar Aedes aegypti. Esta tem forma cilíndrica, cor escura, formando três compartimentos, sendo um para isca, um para entrada do adulto e outro para retê-lo dentro da armadilha. Tanto no laboratório quanto no campo, os ensaios mostraram que a armadilha apresentou positividade na captura de adulto de Ae. aegypti. Esses ensaios sugerem mais estudos para avaliar a especificidade da Adultrap para capturar esta espécie.

PALAVRAS-CHAVE. Adultos; armadilha; mosquitos.

Os mosquitos utilizam vários estímulos para identificação e localização de seus hospedeiros, abrigos e recipientes para oviposição. Esses estímulos são desencadeados pelas características físicas, cor, textura do substrato, odor químico, luminosidade, temperatura e presença de água (Bentley e Day e 1989 Bowen 1991). As armadilhas com iscas gás carbônico, luz, animal ou estímulo visual, usualmente são seletivas e orientadas para capturar mosquito que estão voando (Service 1993). Portanto, a escolha do método ou armadilha para uma espécie alvo envolve opção no uso de um ou mais desses atrativos, para maximizar o número de mosquito adulto capturado (Service 1993). Esta nova armadilha visa capturar adultos de Aedes aegypti (Adultrap) utilizando a água como isca atrativa, semelhantemente a armadilha de oviposição (ovitrampa), dado que esta apresenta elevada sensibilidade na detecção de Aedes aegypti e Aedes albopictus (Chadee et al. 1993). A forma arredondada e a cor escura estão sendo consideradas estímulos visuais, pois simulam local tranqüilo para repouso dos mosquitos adultos, da mesma forma que a presença da água representa a condição para oviposição.

O objetivo deste relato é apresentar a descrição da Adultrap, acompanhada de dois ensaios preliminares, um de laboratório e outro de campo.

Teste de laboratório: Confeccionou-se uma gaiola com dimensões de 0.50 X 0.50 X $0.50 \mathrm{~m}$. Duas Adultraps foram colocadas dentro da mesma. Uma contendo água de torneira e outra água fenada a 10\% (Chadee et al. 1995). Em seguida, foram colocadas 61 fêmeas ingurgitadas com sangue de hamster e 22 machos. A partir do dia seguinte, a gaiola foi examinada diariamente, durante duas horas, para verificar se nela havia Ae.aegypti. Teste de campo: Num bairro da cidade de Foz de Iguaçu, Estado do Paraná, Brasil, com Índice de Infestação Predial em torno de 1,5\%, 120 casas foram selecionadas por meio de sorteio baseado no cadastro existente no Banco de Reconhecimento Geográfico da Prefeitura. As Adultraps, com água de torneira foram instaladas no peridomicílio de 60 casas. Noutros 60 as Adultraps tinham água fenada. O período do ensaio foi de 17 a 19 de março de 2004. As Adultraps ficaram expostas pelo tempo de 24 horas ininterruptas. A identificação das espécies de mosquito foi realizada no laboratório.

A armadilha trata-se de uma peça côncava com ponto de fixação (A) e um diâmetro de $24 \mathrm{~cm}$ (B). Na parte central tem uma abertura de $7 \mathrm{~cm}$ de diâmetro e uma borda de $4 \mathrm{~cm}$ de altura voltado para parte interna $(\mathbf{C})$ que serve de conexão à peça $\mathbf{D}$. Esta é formada por quatro cones transparentes $(\mathbf{E})$, contendo orifícios centrais, com diâmetro de $1,0 \mathrm{~cm}$ e inclinados para as laterais da armadilha. Uma tela fina com 54 orifícios/ $\mathrm{cm}^{2}(\mathbf{F})$ isola a água ou a isca atrativa do corpo da armadilha, separando as peças $\mathbf{D}$ e G. Este recipiente tem diâmetro superior de $14,5 \mathrm{~cm}$ e uma base de $8,5 \mathrm{~cm}$ com capacidade para $600 \mathrm{ml} \mathrm{de}$ água (Figura 1). A lateral da armadilha está composta de quatro 


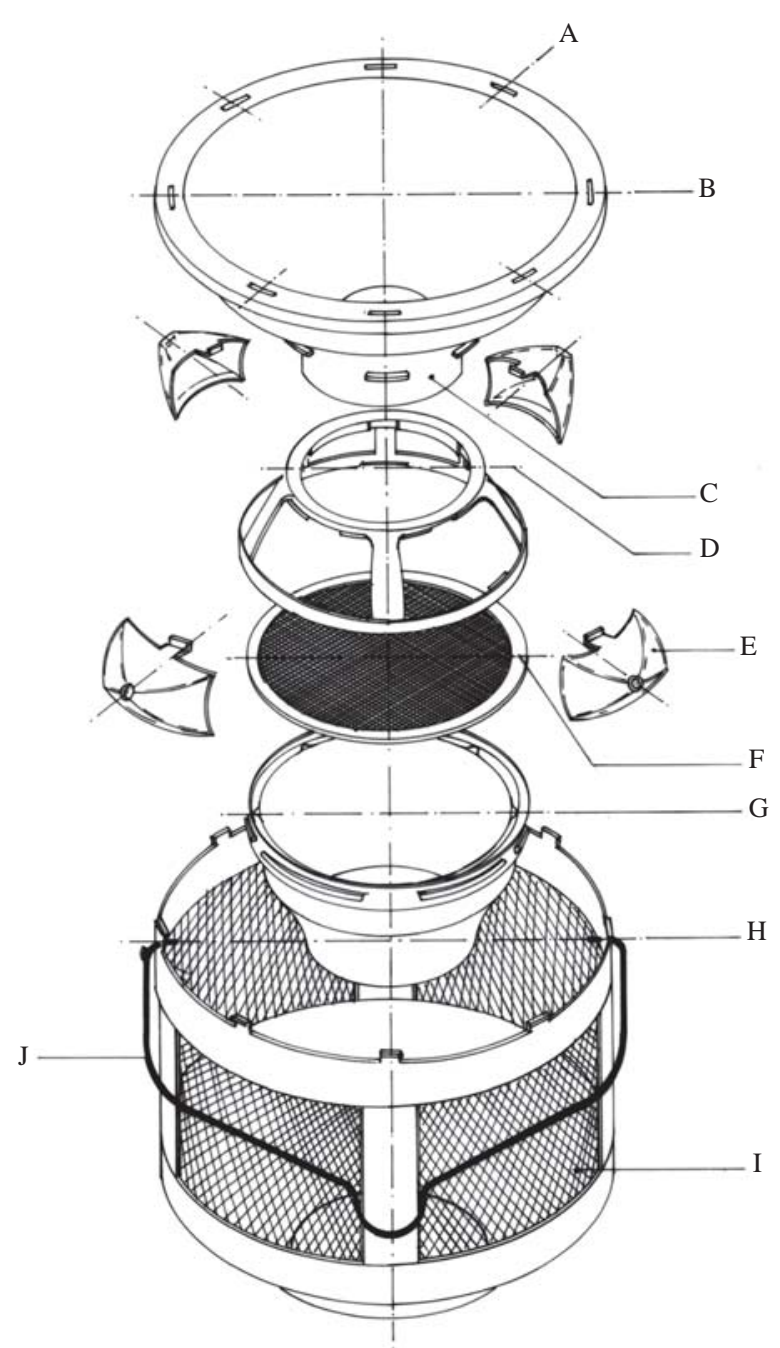

Fig. 1. Peças que compõem a armadilha Adultrap para adulto de Aedes aegypti.

\begin{tabular}{ll}
\hline A - Pontos de fixação & F - Tela \\
B - Peça convexa superior & G - Cuba para água \\
C - Borda da peça convexa & H - Peça telada \\
D - Peça para fixação dos cones & I - Tela \\
E - Cones transparentes & J - Alça \\
\hline
\end{tabular}

placas da mesma tela (I) medindo $15 \mathrm{~cm}$ de comprimento e 10,5 $\mathrm{cm}$ de largura fixadas em colunas de plástico mais rígido $\mathbf{( H )}$. Seus orifícios minúsculos permitem passagem de ar e um certo grau de luminosidade natural. $\mathrm{O}$ diâmetro dessa peça mede 24 cm completando o corpo da armadilha. O conjunto e a montagem de todas as peças resultam na formação de dois compartimentos. O primeiro serve para a entrada do mosquito e o segundo para retê-los entre os cones e a parede de tela. Uma alça (J) externa serve para fixá-la no domicílio ou transportá-la manualmente ao laboratório.

O resultado da captura de adultos Ae. aegypti pelas Adultraps do laboratório foi de $34(73,9 \%)$ para fêmeas na armadilha com feno e $12(26,1 \%)$ para macho. Na Adultrap com água de torneira foram $22(75,8 \%)$ fêmeas e 7 (24,9\%) machos. Cinco fêmeas e três machos morreram dentro da gaiola. No campo, as Adultraps com feno capturaram 9 fêmeas, e a com água de torneira 15. Machos não foram encontrados dentro das mesmas. Essas informações mostram a positividade da adultrap para adulto de Ae. aegypti, particularmente fêmeas, suscitando novos estudos para avaliar sua especificidade na captura desta espécie e de Ae. albopictus.

Agradecimentos. Agradecemos as equipes de entomologia da Secretaria Estadual de Saúde do Estado do Paraná e do Centro de Zoonoses do Municipal de Foz de Iguaçu, pelos ajustes na confecção da adultrap.

\section{REFERÊNCIAS}

Bentley, M. D. \& J. F. Day. 1989. Chemical ecology and behavioral aspects of mosquito oviposition. Annual Review Entomology 34: 401-421.

Bowen, M. F. 1991. The sensory physiology of host-seeking behavior in mosquitoes. Annual Review Entomolology 36: 139-158.

Chadee, D. D.; A. Lakhan; W. R. Ramdath \& R. C. Persad. 1993. Oviposition response of Aedes aegypti mosquitoes to different concentrations of hay infusion in Trinidade, West Indies. Journal of American Mosquito Control Association 9: 346-348.

Chadee, D. D.; P. S. Corbet \& H. Talbot. 1995. Proportions of eggs laid Aedes aegypti on different substrates within an ovitrap in Trinidad, Westy Indies. Medical and Veterinary Entomology 9: 66-70.

Service, M. W. 1993. Sampling the adult resting population, p. 210290. In: Service, M. W. Mosquito ecology: field sampling methods. $2^{\mathrm{a}}$ ed. London, Elsevier Applied Science. 989 p. 